\title{
Dynamic properties of partially denervated muscle in children with brachial plexus birth palsy
}

\author{
M STEFA NOVA-UZ UNOVA, L STA M A T O VA, \\ A N D V G A T E V \\ From the Department of Developmental Physiology, Research Institute of Pediatrics, Sofia
}

\begin{abstract}
SUMMARY Contraction time, time to peak rate of tension development, half-relaxation time and maximum twitch tension of partially denervated flexor carpi ulnaris muscle were measured in children with brachial plexus birth palsy. The extent of weakness of the affected muscle was assessed by expressing its maximum twitch tension as a percentage of the tension of the contralateral normal muscle. Contraction time, time to peak rate and half-relaxation time were prolonged in children with severe weakness, while in children with moderate weakness only halfrelaxation time was prolonged. The contralateral normal flexor carpi ulnaris muscle showed age differences in its contractile properties, while in the affected muscle such differences were not found. This result suggests that denervation at birth impairs normal development of muscle contractile properties.
\end{abstract}

Partial denervation and reinnervation of muscle has been known to produce changes in its contractile properties. ${ }^{1-4}$ It has been shown that denervation and reinnervation also influence the process of muscle fibre differentiation. ${ }^{5-11}$ Few studies are available that assess the contractile properties of partially denervated muscles in patients. ${ }^{12-15}$ It appears worthwhile to investigate the changes in the dynamic properties by partial denervation in human developing muscle.

The purpose of this paper is to describe the changes found in the dynamic properties of partially denervated flexor carpi ulnaris muscle in infants and small children with brachial plexus birth palsy.

\section{Patients and methods}

Seventeen children, eight girls and nine boys, whose ages ranged from two months to three years (mean age 16 months) with brachial plexus birth palsy were examined. The distribution of motor weakness lay within the segmental innervation of roots $C_{5}-T_{1}$. Needle electromyography revealed evidence of partial denervation. The brachial palsy was unilateral; in 13 children it was right-sided, and in four-left-sided. The duration of the palsy was the same as the age of the children.

Address for reprint requests: Dr $M$ Stefanova-Uzunova, Research Institute of Pediatrics, 11 D Nestorov Str, Sofia 1606, Bulgaria.

Accepted 13 January 1981
Electrical and mechanical isometric twitch responses of the flexor carpi ulnaris muscle of both forearms (the normal forearm served as control) were studied. The ulnar nerve was stimulated (single square electric pulses of $0.2-0.5 \mathrm{~ms}$ duration) proximal to the elbow with bipolar surface electrodes Disa $13 \mathrm{~K} 62$. The stimulus intensity was supramaximal $(40 \%$ above maximal). The electrical responses were recorded with bipolar surface electrodes Disa 13K60, placed in bellytendon position and recorded by Disa 3-channel electromyograph. The electrical responses served to control the stimulus strength. The mechanical response was studied by the method of Gatev et al. ${ }^{16}$ The arm was immobilised with a special splint, on which a mechano-electrical transducer was fixed. The dynamogram and its first derivative were recorded (fig 1). Recording and measurement on a photographic paper included electrical response, maximum twitch tension (P), contraction time (CT), time to peak rate of tension development $\left(\mathrm{CT}_{1}\right)$, time from peak rate to the end of contraction $\left(\mathrm{CT}_{2}\right)$, and half-relaxation time $\left(T \frac{1}{2} R\right)$. Measurements of each parameter are illustrated in fig 2 . The individual values of each child were averaged from six to 10 recordings. Further details of the technique and the method have been reported elsewhere. ${ }^{17}$

The extent of weakness of the flexor carpi ulnaris muscle was assessed by expressing its maximum twitch tension as a percentage of the tension of the contralateral normal muscle. The children were divided into two groups according to the extent of muscle weakness. The group with moderate weakness consisted of children with tension decrease of the affected 


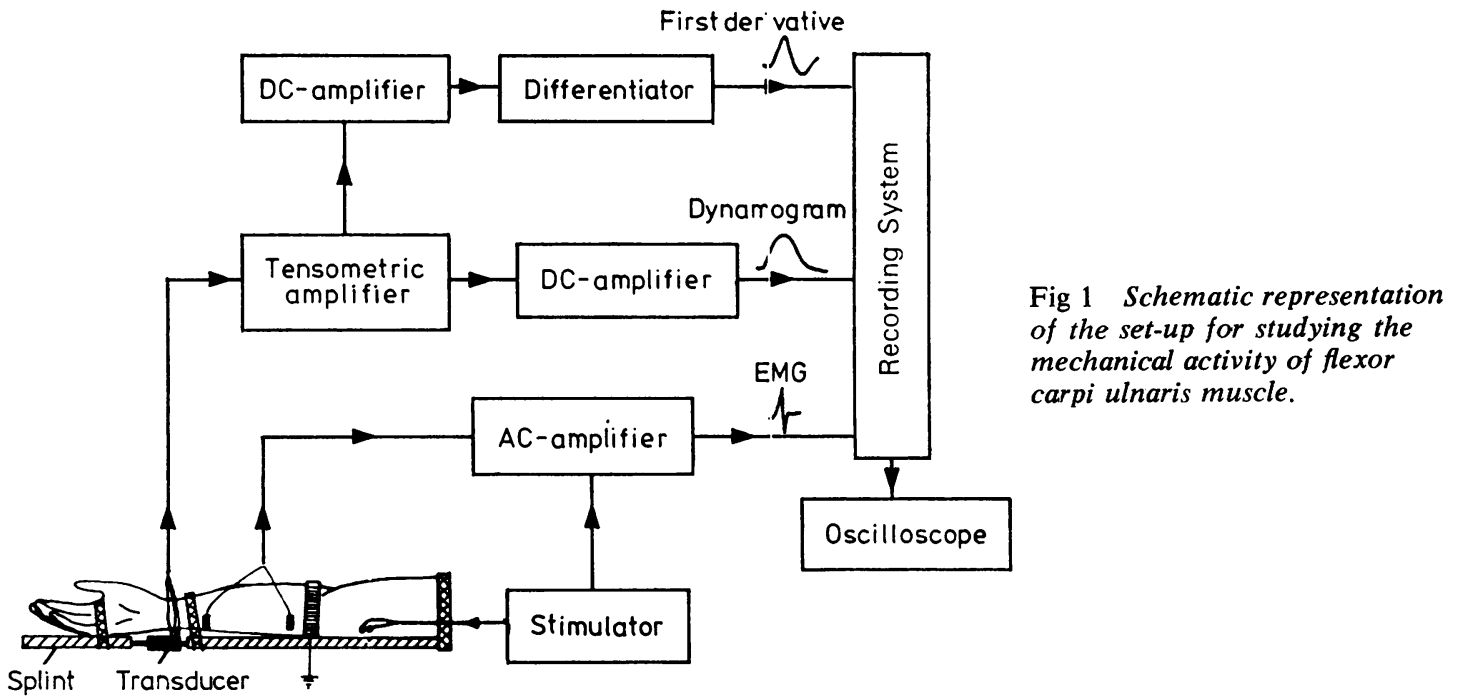

Splint Transducer
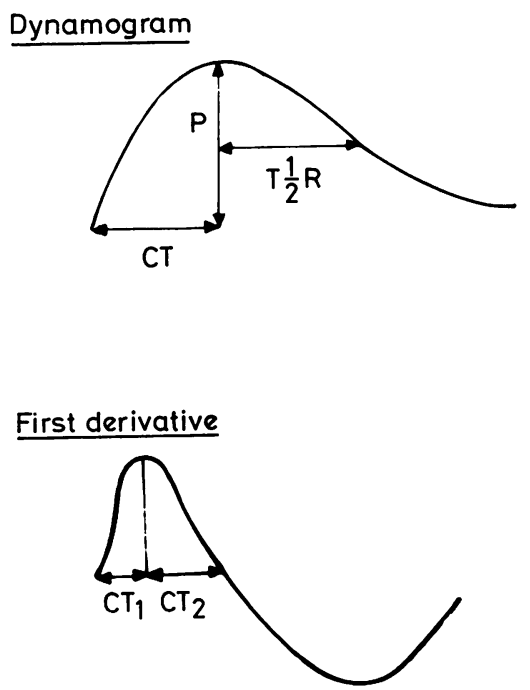

Fig 2 Schematic drawing of the manner of measuring the examined parameters: contraction time $(C T)$; half-relaxation time $\left(T \frac{1}{2} R\right)$; maximum twitch tension $(P)$; time to peak rate of tension development $\left(C T_{1}\right)$; time from peak rate to the end of contraction $\left(\mathrm{CT}_{2}\right)$.

muscle up to $50 \%$ of the tension of the contralateral muscle. In the group with severe weakness there were children with tension decrease exceeding $50 \%$ of the tension of the contralateral muscle. With moderate weakness were seven children, and with severe weakness 10 children. The results are given as the mean \pm standard error (SE). The significance of differences were evaluated by $t$ test and paired $t$ test.

\section{Results}

Twitch tension (table 1) In the group of children with moderate weakness the maximum twitch te:asion of the affected muscle expressed as percentage of the normal muscle was $55.4 \%$, and in the group with severe weakness it was $21.0 \%$. The twitch tension difference between affected and normal muscle was significant in the group with severe weakness $(p<0.001)$, as well as in the group with moderate weakness $(\mathrm{p}<0.01)$. There was, however, a wide scatter of results in maximum twitch tension of the normal muscle. This variability reflects individual and age differences of muscle twitch tension.

Contraction time (table 2) In the moderate and in the severe groups, CT was longer, in the affected muscle than in the normal one, but the difference between them was significant only in children with severe weakness $(p<0 \cdot 01)$. The mean difference in CT between affected and normal muscles in children with severe weakness was greater than that in children with moderate weakness $(p<0.01)$, evaluated by $t$ test.

Time to peak rate of tension development (table 3) In children with severe extent of weakness $\mathrm{CT}_{1}$ was longer in the affected muscle than in the normal one $(p>0.02)$, while in children with moderate weakness no significant difference was found $(\mathrm{p}<0.05)$. The mean difference in $\mathrm{CT}_{1}$ between affected and normal muscles in children with moderate weakness did not differ significantly from the difference in severe weakness ( $p>0.05)$. Time from peak rate to the end of contraction (table 4) This parameter was prolonged in the 
affected muscle in children with severe weakness $(\mathrm{p}<0.01)$ and it tended to be prolonged in children with moderate weakness $(0 \cdot 10>p>0 \cdot 05)$. The mean difference in $\mathrm{CT}_{2}$ in children with severe weakness was greater than the mean difference in children with moderate weakness $(\mathrm{p}<0.02)$.

Half-relaxation time (table 5) In the affected muscle $T \frac{1}{2} R$ was longer than in the normal muscle in children with severe weakness $(p<0.002)$, as well as in children with moderate weakness $(p<0.02)$. The mean difference in $T \frac{1}{2} R$ between affected and normal muscles in children with severe weakness was greater than that in moderate weakness $(\mathrm{p}<0 \cdot 01)$.
Age differences In order to see whether there are any age differences in the examined parameters of the normal and of the affected muscles, the patients were divided into two age groups: infants (aged two to 12 months, mean age five months and 26 days) and children (aged one to three years, mean age two years). The results of this age grouping are given in fig 3 . No significant differences in any of the examined parameters were found in the affected muscle between the two age groups. In the normal muscle significant prolongation of $C T$ and $\mathrm{CT}_{2}(\mathrm{p}<0.05$ for both) and a tendency to significance in $\mathrm{CT}_{1}(0 \cdot 10>\mathrm{p}>005)$ was found in children compared with infants.

Table 1 Maximum twitch tension of flexor carpi ulnaris muscle in children with brachial plexus birth palsy

\begin{tabular}{|c|c|c|c|c|c|}
\hline \multicolumn{2}{|c|}{ Extent of muscle weakness } & \multicolumn{2}{|c|}{ Maximum twitch tension $(\mathrm{g})$} & \multirow[t]{2}{*}{$d(N-A)$} & \multirow[t]{2}{*}{$p$} \\
\hline & & Affected muscle $(A)$ & Normal muscle $(N)$ & & \\
\hline Moderate $n=7$ & $\begin{array}{l}\bar{x} \\
\text { SE } \\
\text { Range }\end{array}$ & $\begin{array}{l}156 \cdot 0 \\
35 \cdot 8 \\
62 \cdot 2-317 \cdot 0\end{array}$ & $\begin{array}{l}286 \cdot 4 \\
66 \cdot 2 \\
103 \cdot 0-573 \cdot 3\end{array}$ & $\begin{array}{l}130 \cdot 3 \\
31 \cdot 6 \\
42 \cdot 1-206 \cdot 8\end{array}$ & $<0.01$ \\
\hline Severe $n=10$ & $\begin{array}{l}\bar{x} \\
\text { SE } \\
\text { Range }\end{array}$ & $\begin{array}{l}52 \cdot 1 \\
9 \cdot 9 \\
22 \cdot 1-130 \cdot 1\end{array}$ & $\begin{array}{l}249 \cdot 0 \\
15 \cdot 8 \\
152 \cdot 7-324 \cdot 4\end{array}$ & $\begin{array}{l}196 \cdot 9 \\
14 \cdot 5 \\
95 \cdot 4-250 \cdot 7\end{array}$ & $<0.001$ \\
\hline
\end{tabular}

$\mathrm{n}$-number of children; $\overline{\mathrm{x}}$-mean; SE-standard error; $d$-mean difference between normal and affected muscles; $p$-statistical significance evaluated by paired $t$ test.

Table 2 Contraction time of flexor carpi ulnaris muscle in children with brachial plexus birth palsy

\begin{tabular}{|c|c|c|c|c|c|}
\hline \multicolumn{2}{|c|}{ Extent of muscle weakness } & \multicolumn{2}{|c|}{ Contraction time $(m s)$} & \multirow[t]{2}{*}{$d(A-N)$} & \multirow[t]{2}{*}{$p$} \\
\hline & & Affected muscle $(A)$ & Normal muscle $(N)$ & & \\
\hline Moderate $\mathrm{n}=7$ & $\begin{array}{l}\bar{x} \\
\text { SE } \\
\text { Range }\end{array}$ & $\begin{array}{l}55 \cdot 2 \\
2 \cdot 0 \\
49 \cdot 0-66 \cdot 2\end{array}$ & $\begin{array}{l}52 \cdot 9 \\
3 \cdot 6 \\
41 \cdot 8-72 \cdot 5\end{array}$ & $\begin{array}{l}2 \cdot 3 \\
1 \cdot 7 \\
0 \cdot 5-7 \cdot 1\end{array}$ & $>0.05$ \\
\hline Severe $n=10$ & $\begin{array}{l}\bar{x} \\
\text { SE } \\
\text { Range }\end{array}$ & $\begin{array}{l}66 \cdot 1 \\
3 \cdot 3 \\
56 \cdot 5-87 \cdot 5\end{array}$ & $\begin{array}{l}49 \cdot 9 \\
1 \cdot 6 \\
43 \cdot 5-57 \cdot 5\end{array}$ & $\begin{array}{l}16 \cdot 1 \\
3 \cdot 8 \\
0 \cdot 6-42 \cdot 0\end{array}$ & $<0.01$ \\
\hline
\end{tabular}

$\mathrm{n}-$ number of children; $\overline{\mathrm{x}}$-mean; SE—standard error; $d$-mean difference between affected and normal muscles; $p$-statistical significance evaluated by paired $t$ test.

Table 3 Time to peak rate of tension development of flexor carpi ulnaris muscle in children with brachial plexus birth palsy

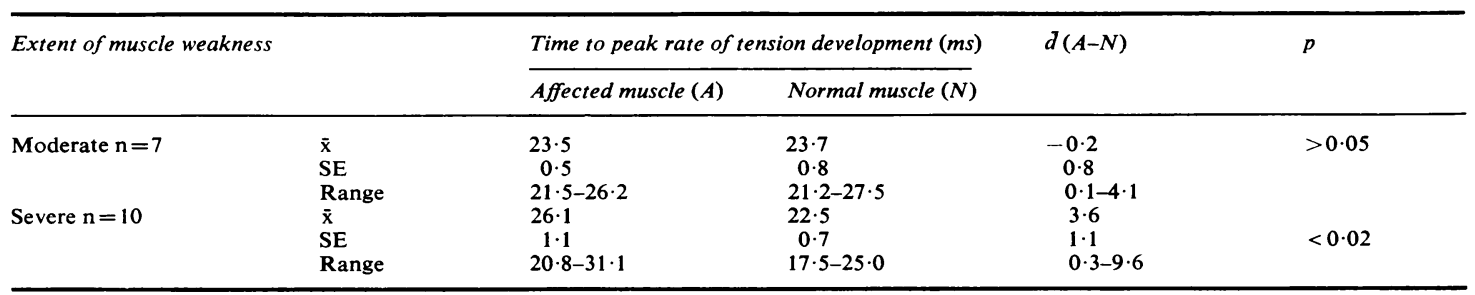

$\mathrm{n}$-number of children; $\overline{\mathrm{x}}$-mean; SE—standard error; $d$-mean difference between affected and normal muscles; $p$-statistical significance evaluated by paired $t$ test. 
Table 4 Time from peak rate to the end of contraction of flexor carpi ulnaris muscle in children with brachial plexus birth palsy

\begin{tabular}{|c|c|c|c|c|c|}
\hline \multicolumn{2}{|c|}{ Extent of muscle weakness } & \multicolumn{2}{|c|}{ Time from peak rate to the end of contraction } & \multirow[t]{2}{*}{$d(A-N)$} & \multirow[t]{2}{*}{$p$} \\
\hline & & Affected muscle $(A)$ & Normal muscle $(N)$ & & \\
\hline Moderate $\mathbf{n}=7$ & $\begin{array}{l}\overline{\mathbf{x}} \\
\text { SE } \\
\text { Range }\end{array}$ & $\begin{array}{l}31 \cdot 7 \\
1 \cdot 9 \\
27 \cdot 5-42 \cdot 9\end{array}$ & $\begin{array}{l}29 \cdot 3 \\
2 \cdot 9 \\
20 \cdot 6-45 \cdot 0\end{array}$ & $\begin{array}{l}2 \cdot 4 \\
1 \cdot 2 \\
1 \cdot 0-6.9\end{array}$ & $0.10>p>0.05$ \\
\hline Severe $n=10$ & $\begin{array}{l}\overline{\mathbf{X}} \\
\text { SE } \\
\text { Range }\end{array}$ & $\begin{array}{l}39 \cdot 8 \\
2 \cdot 9 \\
28 \cdot 5-56 \cdot 5\end{array}$ & $\begin{array}{l}27 \cdot 4 \\
1 \cdot 4 \\
22 \cdot 0-35 \cdot 5\end{array}$ & $\begin{array}{l}12 \cdot 3 \\
3 \cdot 3 \\
1 \cdot 0-32 \cdot 4\end{array}$ & $<0.01$ \\
\hline
\end{tabular}

$\mathrm{n}$-number of children; $\overline{\mathrm{x}}-$ mean; $\mathrm{SE}-$ standard error; $d$-mean difference between affected and normal muscles; $p$-statistical significance evaluated by paired $t$ test.

Table 5 Half-relaxation time of flexor carpi ulnaris muscle in children with brachial plexus birth palsy

\begin{tabular}{|c|c|c|c|c|c|}
\hline \multicolumn{2}{|c|}{ Extent of muscle weakness } & \multicolumn{2}{|c|}{ Half-relaxation time $(\mathrm{ms})$} & \multirow[t]{2}{*}{$d(A-N)$} & \multirow[t]{2}{*}{$p$} \\
\hline & & Affected muscle $(A)$ & Normal muscle $(N)$ & & \\
\hline Moderate $n=7$ & $\begin{array}{l}\overline{\mathbf{x}} \\
\text { SE } \\
\text { Range }\end{array}$ & $\begin{array}{l}58 \cdot 6 \\
3 \cdot 3 \\
45 \cdot 0-74 \cdot 1\end{array}$ & $\begin{array}{l}53 \cdot 1 \\
3 \cdot 2 \\
45 \cdot 5-68 \cdot 1\end{array}$ & $\begin{array}{l}5 \cdot 3 \\
1 \cdot 7 \\
0 \cdot 5-10 \cdot 4\end{array}$ & $<0.02$ \\
\hline Severe $n=10$ & $\begin{array}{l}\bar{x} \\
\text { SE } \\
\text { Range }\end{array}$ & $\begin{array}{l}87 \cdot 4 \\
8 \cdot 0 \\
59 \cdot 5-140 \cdot 0\end{array}$ & $\begin{array}{l}59 \cdot 2 \\
4 \cdot 0 \\
45 \cdot 0-85 \cdot 0\end{array}$ & $\begin{array}{l}28 \cdot 2 \\
6 \cdot 0 \\
6 \cdot 6-55 \cdot 0\end{array}$ & $<0.002$ \\
\hline
\end{tabular}

$\mathrm{n}$-number of children; $\overline{\mathrm{x}}$-mean; SE-standard error; $d$-mean difference between affected and normal muscles; $p$ - - statistical significance evaluated by paired $t$ test

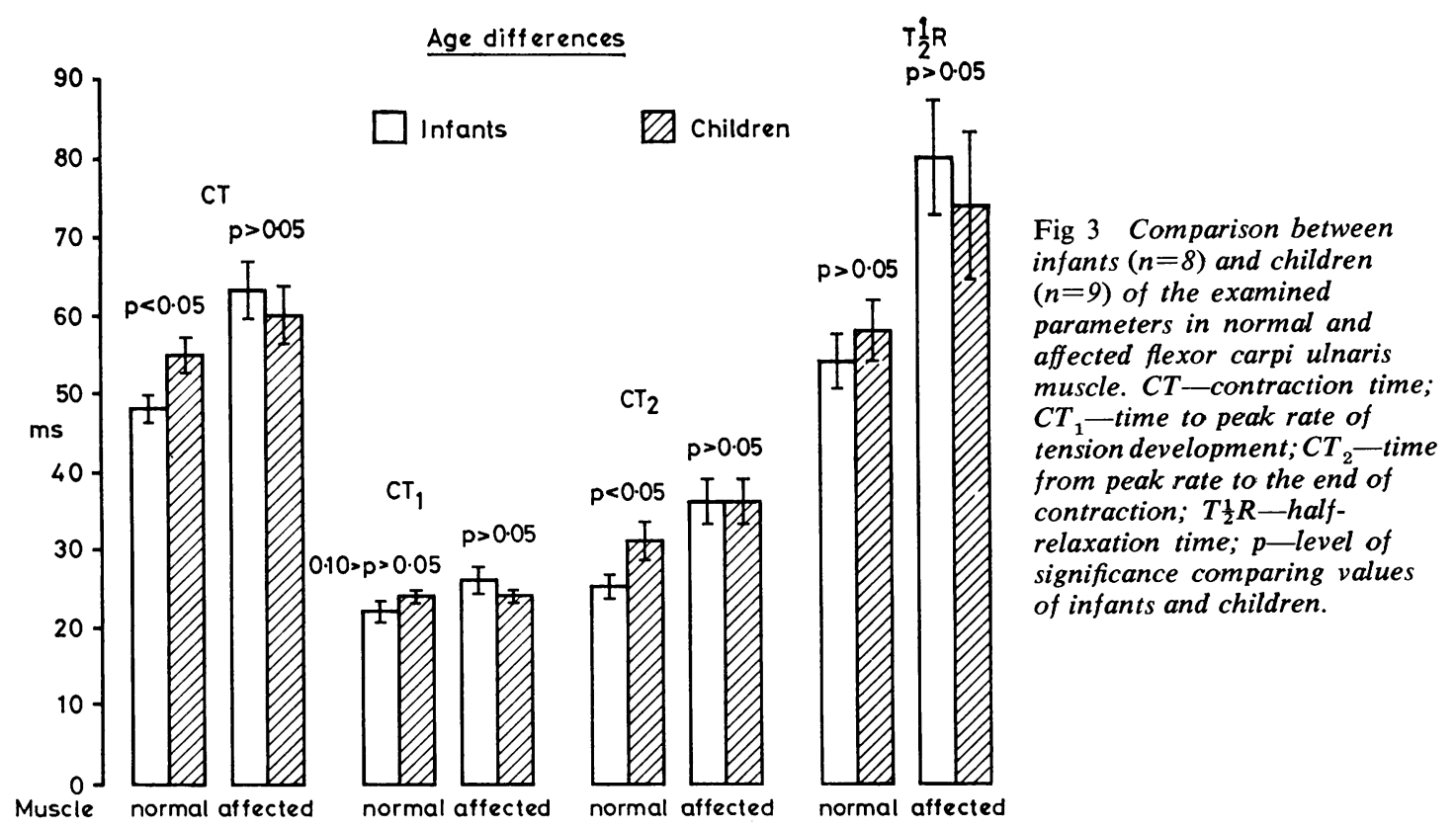

\section{Discussion}

In the present study isometric twitch tension of the paretic flexor carpi ulnaris muscle was compared with that of the contralateral normal muscle in order to assess the extent of the weakness. This gave us the opportunity to study the influence of the extent of the muscle weakness on its con- 
tractile properties. The insignificant difference between twitch tension of the paretic muscle and the normal one in the group with moderate weakness probably results from a slight degree of partial denervation or from a well pronounced process of reinnervation for this extent of weakness or both.

In the present study all examined parameters of the contractile properties of the affected muscle (CT, $\mathrm{CT}_{1}, \mathrm{CT}_{2}$ and $\mathrm{T} \frac{1}{2} \mathrm{R}$ ) were prolonged in the group of children with severe weakness. In children with moderate weakness only $T \frac{1}{2} R$ was prolonged, but this prolongation was considerably smaller than that in those with severe weakness. These results suggest that changes in contractile properties following denervation and reinnervation were influenced by the extent of muscle weakness. Hence, severe denervation and poor recovery of twitch tension were accompanied by slowing of the velocity properties of the muscle.

Studies on partially denervated and reinnervated muscles in adult patients have equivocal findings for CT and $T \frac{1}{2} R \cdot{ }^{12-15}$ Buchthal et al ${ }^{12}$ examining CT of small bundles of muscle fibres in brachial biceps muscle and in anterior tibial muscle in adult patients found prolonged CT and the range of the histogram of CT diminished by $60 \%$. Prolonged $C T$ and $T \frac{1}{2} R$ was found also in partially denervated extensor hallucis brevis muscle, ${ }^{13}$ in the first dorsal interosseus muscle ${ }^{15}$ and in motor units from the same muscle. ${ }^{14}$

The present study confirms earlier ones ${ }^{12-15}$ in showing that there are prolonged $C T$ and $T \frac{1}{2} R$ in partially denervated human muscles but it differs in that it examined a muscle affected at birth and it gave an account of the influence of the extent of muscle weakness on the contractile properties.

The adult pattern of contractile characteristics of mammalian muscles develops before and after birth. 1819 Postnatal development of muscle contractile properties in animals is impaired after denervation. 2591011 In the present study the normal flexor carpi ulnaris muscle showed slowing of its velocity properties in children compared with infants. These changes are similar to the changes found in normal infants and children, ${ }^{17}$ and reflect age differences occurring during development. Such age differences, however, were not found in partially denervated flexor carpi ulnaris, which showed marked prolongation of all examined parameters irrespective of age. Moreover, in several patients the values of CT in the affected muscle were in the range of those found by Gatev et $a l^{17}$ in the slow-twitch triceps surae muscle in normal infants and children. These results suggest that denervation at birth impairs developmental changes of muscle contractile properties, which would normally occur during this age period.

The slowing of muscle contraction in adult patients with denervating process has been assumed to be the result of an unusually high proportion of slow fibres, ${ }^{12}$ and slow twitch units, ${ }^{1314}$ among the surviving population. This assumption was based on the finding of an increase of cross-sectional area of slow fibres in muscles of patients with lesions of the brachial plexus, ${ }^{12}$ and of a predominance of motor units with longer CT in patients with neuropathies. ${ }^{14}$

The slowing of the velocity properties of partially denervated muscle in man might be due to changes in the contractile component of the muscle, or to changes in the muscle's series-elastic element. Time to peak rate of tension development depends on the duration of the active state, which reflects mainly the properties of the contractile component. The rate of muscle relaxation depends on the decay of active state, which reflects the kinetics of cross-bridge turnover, and the properties of the muscle's series-elastic element. ${ }^{19}$ The present study demonstrates that time-to-peak rate was prolonged in severe partial denervation, so it is reasonable to suggest that the contractile component of the muscle is involved. However, it is very likely that muscle series-elastic element also is involved after denervation by proliferation of connective tissue in the muscle, resulting in prolongation of $T \frac{1}{2} R$. Reduced rate of relaxation has been found in diseases quite different from denervation, such as progressive muscular dystrophy ${ }^{21}$ and in hypothyroidism. ${ }^{22}{ }^{23}$ Therefore it is probable that different factors and mechanisms are involved in these changes.

\section{References}

1 Bagust J, Lewis DM. Isometric contractions of motor units in self-reinnervated fast and slow twitch muscles of the cat. J Physiol (London) 1974; 237:91-102.

2 Gutmann E, Melichna J A, Herbrychová A, Stichová J. Different changes in contractile and histochemical properties of reinnervated and regenerated slow soleus muscles of the guinea-pig. Pflügers Arch 1976; 364:191-4.

3 Huizar P, Kuno M, Kudo N, Miyata Y. Reaction of intact spinal motoneurones to partial denervation of the muscle. J Physiol (London) 1977; 265: 175-91.

4 Chan HS, Westerman RA, Ziccone SP. Modification of motor units in fast twitch muscle after 
partial denervation. J Physiol (London) 1978; 281:29-30.

5 Buller AJ, Eccles JC, Eccles RM. Differentiation of fast and slow muscles in the cat hind limb. J Physiol (London) 1960; 150:399-416.

6 Karpati G, Engel WK. Neuronal trophic function. A new aspect demonstrated histochemically in developing soleus muscle. Arch Neurol 1967; 17: 542-5.

7 Engel WK, Karpati G. Impaired skeletal muscle maturation following neonatal neurectomy. Devl Biol 1968; 17:713-23.

8 Lewis DM. The effect of denervation on the differentiation of twitch muscles in kitten hind limb. Nature 1973; 241:285-6.

9 McArdle JJ, Sansone FM. Re-innervation of rat fast and slow twitch muscle following nerve crush at birth. J Physiol (London) 1977; 271: $567-86$.

10 Gutmann E, Melichna JA. Contractile and histochemical properties of denervated and reinnervated fast and slow skeletal muscles of new-born and adult guinea-pigs. Physiol Bohemoslov 1979; 28:35-42.

11 Westerman RA, Chan HS, Ziccone SP. Sriratana D, Dennett X, Tate KA. Plasticity of motor reinnervation in the kitten. In: Meisami E, Brazier MAB, eds. Neurol Growth and Differentiation. New York: Raven Press 1980: 397-432.

12 Buchthal F, Schmalbruch H, Kamieniecka Z. Contraction time and fiber types in neurogenic paresis. Neurology (Minneap) 1971; 21:58-67.

13 McComas AJ, Sica REP, Campbell MJ, Upton ARM. Functional compensation in partially denervated muscles. J Neurol, Neurosurg Psychiatry 1971; 34:453-60.
14 Milner-Brown HS, Stein RB, Lee RG. Contractile and electrical properties of human motor units in neuropathies and motor neurone disease. $J$ Neurol, Neurosurg Psychiatry 1974; 6:670-6.

15 Miller RG. Dynamic properties of partially denervated muscle. Ann Neurol 1979; 6:51-5.

16 Gatev V, Ivanov I, Stamatova L, Angelova B. A method and device for investigating the maximal muscle force in infants and toddlers. Patent N 30582, Institute of Inventions and Rationalizations, Sofia 1975 (in Bulgarian).

17 Gatev V, Stamatova L, Angelova B. Contraction time in skeletal muscles of normal children. Electromyog Clin Neurophysiol 1977; 17:441-52.

18 Close R. Dynamic properties of fast and slow skeletal muscles of the rat during development. J Physiol (London) 1964; 173:74-95.

19 Close R. Dynamic properties of mammalian skeletal muscles. Physiol Rev 1972; 52:129-97.

20 Desmedt JE, Emeryk B, Renoirte P, Hainaut K. Disorder of muscle contraction processes in sexlinked (Duchenne) muscular dystrophy, with correlative electromyographic study of myopathic involvement in small hand muscles. Am J Med $1968 ; 45: 853-72$.

21 Takamori M. Contractility and supersensitivity to adrenaline in dystrophic muscle. J Neurol, Neurosurg, Psychiatry 1975; 38:483-92.

22 Takamori M, Gutmann L, Shane SR. Contractile properties of human skeletal muscle. Normal and thyroid disease. Arch Neurol 1971; 25:535-46.

23 Wiles CM, Young A, Jones DA, Edwards RHT Muscle relaxation rate, fiber-type composition and energy turnover in hyper- and hypo-thyroid patients. Clin Sci 1979; 57:375-84. 